\title{
Genetic susceptibility testing versus family history- based risk assessment: Impact on perceived risk of Alzheimer disease
}

Susan LaRusse, $M S^{1}$, J. Scott Roberts, $P h D^{2}$, Theresa M. Marteau, $P h D^{4}$, Heather Katzen, $P h D^{5}$, Erin L. Linnenbringer, $M S^{3}$, Melissa Barber, $M S^{6}$, Peter Whitehouse, $M D, P h D^{6}$, Kimberly Quaid, $P h D^{7}$, Tamsen Brown, $M S^{3}$, Robert C. Green, $M D, M P H^{2,3,8}$, and Norman R. Relkin, $M D, P h D^{5}$

\begin{abstract}
Purpose: We examined how an Alzheimer disease (AD) family history assessment as compared to a risk assessment incorporating the absence of a disease-associated susceptibility allele affected risk perception among adult children with a family history of AD. Methods: The REVEAL study is a clinical trial in which adult children of patients with $A D$ were randomized to receive a risk assessment based upon family history alone or family history plus apolipoprotein $\mathrm{E}(A P O E)$ disclosure. In this analysis, two subsets of women were identified, each of whom received identical 29\% lifetime risk estimates of developing AD. One group received a risk estimate that incorporated $A P O E \epsilon 4$-negative genetic test results (Genotype Group, $n=30$ ), whereas the other received a risk estimate based on family history and gender (Family History Group, $n=36$ ). Six weeks after risk disclosure, we surveyed participants regarding the impact of the risk assessment on their perceptions of AD risk. Results: $73 \%$ of the Genotype Group judged their risk to be lower compared to $25 \%$ of the Family History Group $(P<0.0001)$. $67 \%$ of the Genotype Group reported lower anxiety about AD, versus $26 \%$ of the Family History Group $(P<0.01)$. $80 \%$ of the Genotype Group indicated that the risk information had a positive impact, versus $36 \%$ of the Family History Group ( $P<0.001)$. The Genotype Group was less likely to believe that they would develop AD $(13 \%$ vs. $36 \%$, $P<0.05$ ) and was more likely to report that the risk assessment removed uncertainty about their chances of developing $A D(63 \%$ vs. $9 \%, P<0.0001)$. Conclusions: These data suggest that risk estimates incorporating negative genetic test results affect perceptions of disease susceptibility more strongly than identical estimates based on family history alone. Genet Med 2005:7(1):48-53.
\end{abstract}

Key Words: genetic susceptibility testing, Alzheimer disease, APOE, risk perception, genetic counseling

Alzheimer disease $(\mathrm{AD})$ is a complex late-onset, degenerative disease known to have a substantial genetic component. There are three known genes associated with the early-onset autosomal dominant form of $\mathrm{AD}$, but these genes account for $<2 \%$ of $\mathrm{AD}$ cases. $^{1}$ The gene associated with the much more common late-onset $\mathrm{AD}$, the $\epsilon 4$ allele of the apolipoprotein $\mathrm{E}$ $(A P O E)$ gene, ${ }^{2}$ is relatively common in the general population with approximately $25 \%$ of individuals carrying at least one $\epsilon 4$

\footnotetext{
From ${ }^{1}$ Taub Institute for Research on Alzheimer's Disease and the Aging Brain, Columbia University, New York, New York; Departments of ${ }^{2}$ Neurology and ${ }^{3}$ Medicine (Genetics Program), Boston University School of Medicine, Massachusetts; ${ }^{4}$ Department of Health Psychology, King's College, London, UK; ${ }^{5}$ Department of Neurology and Neuroscience, Weill Medical College of Cornell University; ${ }^{6}$ University Memory and Aging Center, Case Western Reserve University/University Hospitals of Cleveland, Ohio; ${ }^{7}$ Department of Medical and Molecular Genetics, Indiana University School of Medicine; and ${ }^{8}$ Department of Epidemiology, Boston University School of Public Health, Boston, Massachusetts.

Susan LaRusse, MS, Columbia University/Taub Institute, 630 W 168th St. PerS Box 16, New York, NY, 10032

Received: July 13, 2004.

Accepted: October 13, 2004
}

DOI: 10.1097/01.GIM.0000151157.13716.6C allele. At the present time, however, genetic testing for lateonset $\mathrm{AD}$ is not widely performed or recommended because of the low predictive value of $A P O E$ genotyping and the lack of proven preventative options. ${ }^{3-6}$ As more $\mathrm{AD}$ susceptibility genes and effective prevention strategies are discovered, it is possible that susceptibility genotyping will be used to provide an individual with probabilistic information about future disease risk. $\mathrm{AD}$ susceptibility genotyping may also be used to identify at-risk individuals for clinical trials, which would also require disclosure of genotype results. ${ }^{7} \mathrm{AD}$ is one of many complex disorders with a genetic component and given the inherent uncertainties of risk information and the rapidly advancing field of genetics, experts in the field have noted a need for multidisciplinary research focused on communication and risk perception in genetic testing: "The expected increasing uncertainty of the implications of the '-omics' era will necessitate a true integration of the field of genetic counseling with health education and communication sciences."

Currently, most asymptomatic individuals who request a risk assessment for $\mathrm{AD}$ are offered a probability based on epidemiologically based risk estimates, ${ }^{17}$ yet epidemiologically 
derived risk estimates may have a minimal impact upon risk perception. ${ }^{9}$ Little is known about the impact of receiving genetic test results, specifically negative results, as part of a risk assessment for a common complex disorder like AD. Studies have shown that genetic information can be perceived as different from other types of disease risk information, ${ }^{10} \mathrm{a}$ concept that has been termed "genetic exceptionalism."11 Studies that have examined the impact of genetic test results on risk perception have come to different conclusions. One study used an analog design for a fictitious disease, with results indicating that positive genetic test results did not cause an increase in perceived risk compared to the family history risk. ${ }^{12}$ In a randomized controlled trial comparing the psychological impact of making or confirming a diagnosis of familial hypercholesterolemia using genetic testing in addition to family history and cholesterol testing, participants whose diagnosis was made using genetic testing perceived their diagnosis as more accurate..$^{13}$ Although it did not examine family history information, another study focusing on biomarkers for smoking concluded that additional risk clarification by a genetic test was associated with an increase in perceived risk. ${ }^{14}$ To our knowledge, no clinical studies have explored whether individuals differentiate between a family history risk assessment and an assessment that incorporates the absence of a risk allele for a complex disorder such as AD.

The REVEAL study (Risk Evaluation and Education for Alzheimer Disease) is the first multicenter randomized clinical trial to evaluate the impact and efficacy of a risk assessment program using APOE genotyping for adult children of people diagnosed with $\mathrm{AD}$. In this report, we examine the impact of an $\mathrm{AD}$ risk assessment protocol incorporating negative genetic test results compared to a family history risk assessment and examine the effect of the two different types of assessments on participants' perceptions of risk. The REVEAL study presented the unique opportunity to explore this subject by allowing a comparison of two subsets of participants who received identical numeric lifetime risk estimates of developing $\mathrm{AD}$, but differed as to whether or not they received $A P O E$ genotype results. Based on the current literature, we expected that the individuals that received a risk assessment based on epidemiological family history data would experience little impact compared to those that received a genetic risk assessment.

\section{MATERIALS AND METHODS}

\section{Overview}

The REVEAL study is the first randomized controlled trial to evaluate the impact of a risk assessment, using APOE genotype disclosure, for AD. The study's methods have been described

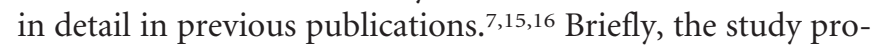
tocol was developed by a multidisciplinary team of experts in the fields of $\mathrm{AD}$, neurology, genetics, genetic counseling, psychology, and bioethics. Development of the protocol was overseen and approved by a study External Advisory Board, as well as institutional review boards at each of the three study sites.
All participants gave written informed consent. The various steps of the REVEAL Study are outlined in Fig. 1.

\section{Risk estimates}

Risk estimates were formulated using two sources: (1) agespecific incidence curves for first-degree relatives of individuals affected by $\mathrm{AD}$ from a genetic epidemiology study of $\mathrm{AD}$ families ${ }^{17-18}$; and (2) odds ratio estimates reported in a metaanalysis encompassing 40 studies worldwide. ${ }^{19}$ Bayes' rule was used to stratify risk according to APOE genotype. ${ }^{16}$ The lifetime risk estimates ranged from $13 \%$ to $57 \%$ depending on an individual's gender and APOE genotype. During the Educational Session and the Disclosure Session of the protocol (Fig. 1), the genetic counselor explained that the affected parent's genotype would not be determined nor used in generating a risk assessment. Risk estimates were presented in oral, visual, and written formats and included in a take-home letter provided to participants. To facilitate communication with participants during the risk disclosure session, risk curves tailored to participant genotype and gender were generated. The genetic counselor met individually with participants in 30- to 60minute risk disclosure sessions to communicate risk, provide

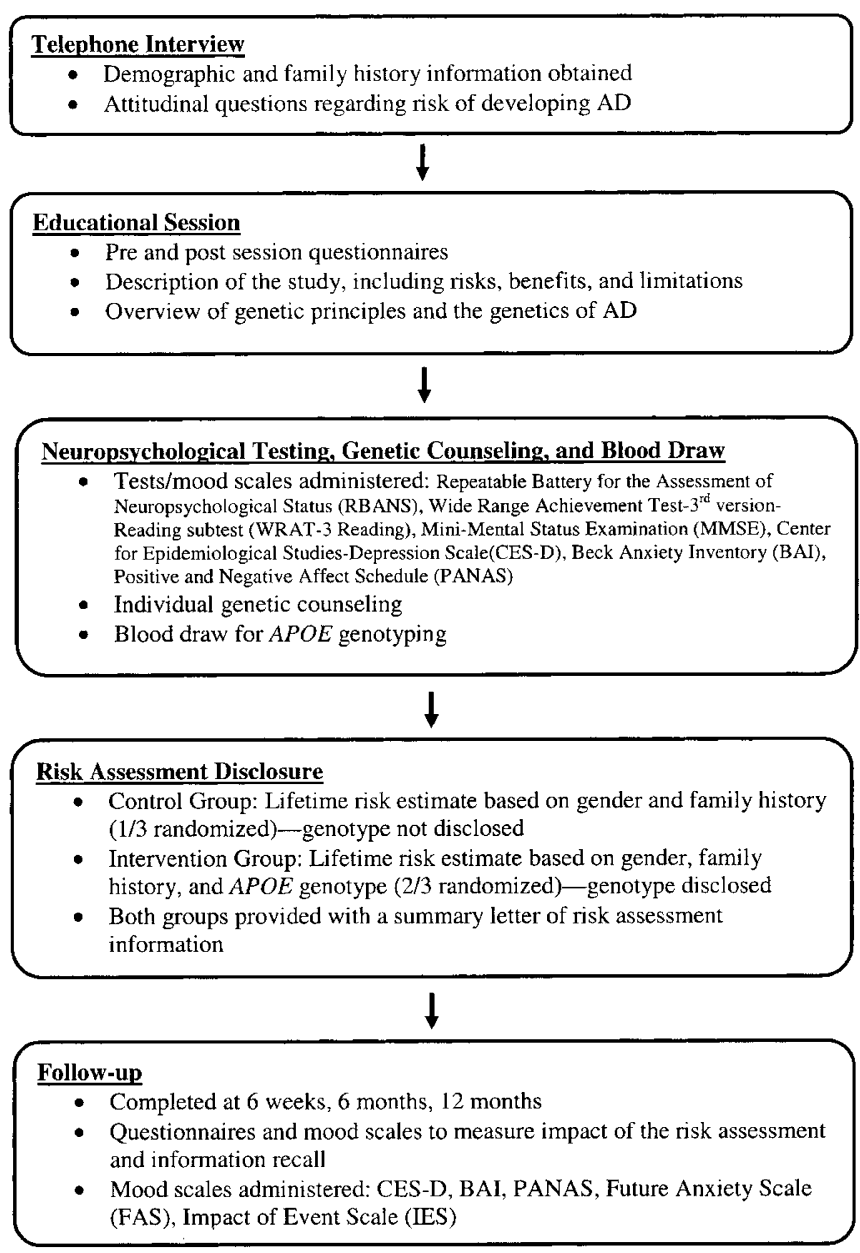

Fig. 1. Flowchart of overall REVEAL study design. 
support, and answer any questions that participants might have.

\section{Participants and procedures}

We analyzed the impact of risk assessment information among a subset of REVEAL participants: specifically, all women who received a lifetime risk estimate based on family history and gender (Family History Group), as well as women who possessed an $A P O E \epsilon 3 / \epsilon 3$ genotype and received a lifetime risk estimate based on genotype, gender, and family history (Genotype Group). Although men were also participants in this study, we chose to compare survey results of women in these two subgroups because both groups received identical lifetime risk estimates of $29 \%$ for developing AD. In the Genotype Group, this estimate was provided in the context of a risk assessment in which their APOE genotype was also disclosed.

\section{Measures}

At 6 weeks after risk disclosure, participants were asked a series of written survey questions designed to assess their perceptions of $\mathrm{AD}$ risk and the impact of risk information. All questionnaires were self-administered and completed on-site, although in rare instances, the questionnaire was mailed to the participant if he or she was unable to come to the site for the follow-up visit. The questions were as follows: (1) "Since having received a risk assessment for $\mathrm{AD}$, would you say that your own chances of developing the disease have seemed" $(1=$ Much lower to $5=$ Much higher); (2) "Since having received risk assessment for $\mathrm{AD}$, how has your anxiety about developing the disease changed?" ( $1=$ Much lower to $5=$ Much higher $)$; (3) "Please rate the overall impact that your risk information has had on you" ( $1=$ Very positive to $5=$ Very negative); (4) "I believe that I will someday develop AD" ( 1 = Strongly agree to $5=$ Strongly disagree); and (5) "Did receiving a risk estimate help to remove uncertainty about your chance of developing AD?" (Yes, no, or undecided). Participants were also posed an open-ended question: "Please briefly describe the nature of the impact the information has had on you."

\section{Data analyses}

Descriptive statistics were used to characterize the sample in terms of its demographics and baseline attitudes about personal risk of $\mathrm{AD}$. A series of chi square analyses was used to examine study group differences on the outcomes of interest, with survey responses dichotomized to facilitate analyses. Covariates were not included in analyses because the two study groups did not differ with respect to age, race, mean years of education, number of relatives with $\mathrm{AD}$ or cognitive deficits, and baseline worry and belief about developing AD. The two groups differed in terms of median income but this covariate was not associated with the outcomes of interest.

\section{RESULTS}

\section{Sample demographics}

The subset of REVEAL participants with identical 29\% lifetime risk estimates consisted of 36 women in the Family His- tory Group and 30 women in the Genotype Group who were homozygous for APOE $\epsilon 3$. Demographic characteristics for both groups are provided in Table 1. Overall, the sample was middle aged, White, of high socioeconomic status, well educated, and had an average of approximately two family members with reported $\mathrm{AD}$ or related memory problems. Participants in the two groups did not differ at baseline with respect to worry or belief about developing AD.

\section{Data analyses}

Questionnaire responses obtained at 6-week follow-ups for the two groups are shown in Table 2. Compared to their counterparts in the Family History Group, women receiving identical risk projections, along with a $\epsilon 3 / \epsilon 3$ genotype result reported lower perceived risk of $\mathrm{AD}$ as a result of test information ( $73 \%$ vs. $25 \%$ reported lower risk, $\chi 2[1, N=66]$ $=15.35 ; P<0.0001)$, lower anxiety about developing $\mathrm{AD}$ as a result of test information ( $67 \%$ vs. $26 \%$ reported lower anxiety, $\chi 2[1, N=64]=10.39 ; P<0.01)$, and a more positive overall impact of test information ( $80 \%$ vs. $36 \%$ reported positive impact, $\left.\chi^{2}[1, N=66]=12.80 ; P<0.001\right)$. A greater number of women in the Family History Group, as compared to the Genotype Group women, agreed with a statement that they believed they would someday develop $\mathrm{AD}(36 \%$ vs. $13 \%$ agreed, $\chi 2[1, N=66]=4.44 ; P<0.05)$. In addition, women receiving a $\epsilon 3 / \epsilon 3$ genotype were more likely to report that test information had helped remove uncertainty about whether they would develop AD (63\% vs. 9\%, $\chi 2[1, N=60]=15.35 ; P<0.0001)$. Not all of the participants in both groups answered all five questions. Although participants also completed follow-up questionnaires at 6 months and 12 months after risk disclosure, only 6 week data are reported here because they reflect the most immediate impact of risk information. Analyses of 6 month and 12 month questionnaire data showed that patterns of response on study outcomes remained unchanged over time.

\section{Qualitative data}

Selected participants' responses on the open-ended question asking for a brief description of the overall impact of the

Table 1

Sample demographics

\begin{tabular}{lcc}
\hline Characteristic & $\begin{array}{c}\text { Family History } \\
\text { Group }(n=36)\end{array}$ & $\begin{array}{c}\text { Genotype Group } \\
(n=30)\end{array}$ \\
\hline $\begin{array}{l}\text { Mean age (years, SD) } \\
\text { Range }\end{array}$ & $53.6(8.4)$ & $54.9(10.7)$ \\
Race $(n, \%$ White) & $37-78$ & $35-75$ \\
Mean years of education (SD) & $32(89 \%)$ & $29 \quad(97 \%)$ \\
$\quad$ Range & $16.8(2.3)$ & $16.0(2.0)$ \\
$\begin{array}{l}\text { Median household income } \\
\text { Number of relatives with memory } \\
\text { problems }\end{array}$ & $12-22$ & $12-21$ \\
Range & $\$ 70,000-\$ 99,000$ & $\$ 50,000-\$ 69,000$ \\
\end{tabular}


Table 2

Responses to survey items assessing perceived risk of $\mathrm{AD}$ and impact of risk information, by study group

\begin{tabular}{|c|c|c|c|}
\hline \multirow[b]{2}{*}{ Survey item } & \multirow[b]{2}{*}{ Response } & \multicolumn{2}{|c|}{$N$ (\% endorsing) } \\
\hline & & Family History Group $(n=36)$ & Genotype Group $(n=30)$ \\
\hline \multirow[t]{3}{*}{ Change in perceived risk of $\mathrm{AD}$ as a result of test info } & Lower & $9(25 \%)$ & $22(73 \%)$ \\
\hline & Same & $26(72 \%)$ & $7(23 \%)$ \\
\hline & Higher & $1(3 \%)$ & $1(3 \%)$ \\
\hline \multirow[t]{3}{*}{ I believe I will develop $\mathrm{AD}$} & Agree & $13(36 \%)$ & $4(13 \%)$ \\
\hline & Undecided & $17(47 \%)$ & $12(40 \%)$ \\
\hline & Disagree & $6(17 \%)$ & $14(47 \%)$ \\
\hline \multirow[t]{3}{*}{ Anxiety about developing $\mathrm{AD}$ as a result of test information } & Lower & $9(26 \%)$ & $20(67 \%)$ \\
\hline & Same & $23(68 \%)$ & $10(33 \%)$ \\
\hline & Higher & $2(6 \%)$ & 0 \\
\hline \multirow[t]{3}{*}{ Overall impact of risk information } & Positive & $13(36 \%)$ & $24(80 \%)$ \\
\hline & Neutral & $20(56 \%)$ & $5(17 \%)$ \\
\hline & Negative & $3(8 \%)$ & $1(3 \%)$ \\
\hline \multirow[t]{3}{*}{ Did risk information help remove uncertainty about developing AD? } & Yes & $3(9 \%)$ & $17(63 \%)$ \\
\hline & No & $22(67 \%)$ & $6(22 \%)$ \\
\hline & Undecided & $8(24 \%)$ & $4(15 \%)$ \\
\hline
\end{tabular}

risk assessment are shown in Table 3. Fifty-five of the 66 participants $(83 \%)$ responded to the question at 6 weeks after disclosure. Responses were chosen for illustrative purposes in support of findings from the quantitative data.

\section{DISCUSSION}

This is the first study to explore the impact on risk perception of incorporating negative genetic test results into a risk assessment for late-onset $\mathrm{AD}$. Our findings suggest that inclusion of a negative genetic test result (i.e., absence of the $\epsilon 4$ allele) resulted in lower perceived risk of $\mathrm{AD}$ as compared to a family history-based risk assessment. Despite receiving the same numerical risk estimate as the Family History Group, the Genotype Group reported comparatively lower anxiety about developing $\mathrm{AD}$ and a more positive impact of test information. These findings are supplemented by our qualitative data. Sev-

Table 3

Selected responses to open-ended question asking about impact of risk information

\begin{tabular}{|c|c|}
\hline Family History Group & Genotype Group \\
\hline It has had no affect. & The information was positive so I do not need to think, worry, or whatever about it. \\
\hline None, because it was no different than I expected. & A little more relief that I got my mom's genes. \\
\hline $\begin{array}{l}\text { I want my children to know my APOE. That is the only reason I agreed } \\
\text { to your study. }\end{array}$ & Feel relieved that I don't have the APOE 4. \\
\hline $\begin{array}{l}\text { Because two of my aunts had the disease, along with my mom, there was } \\
\text { no significant impact, especially because I did not get chosen for gene } \\
\text { disclosure. }\end{array}$ & $\begin{array}{l}\text { A relief by knowing this aspect was not inherited, however, understanding there are } \\
\text { many more factors. }\end{array}$ \\
\hline $\begin{array}{l}\text { It would have been interesting to have learned more, but being in the } \\
\text { control group blocked the information, so I have nothing to base } \\
\text { concern on. }\end{array}$ & $\begin{array}{l}\text { Because my mother and her brothers have AD, I believed I had the APOE } 4 \text { gene } \\
\text { with a better than } 50 \% \text { chance of the disease. Now I believe my risk is at } 25 \% \text {, } \\
\text { and I feel much more positive about the chances of not having AD. I no longer } \\
\text { worry every time I have a memory glitch and am much calmer. }\end{array}$ \\
\hline I feel as though I have the same risk as anyone else. & $\begin{array}{l}\text { It has placed me in the same category of people who do not have an increased risk } \\
\text { due to genetic predisposition ergo I feel more optimistic about the future. }\end{array}$ \\
\hline It was basically what I expected. & I feel my chances of developing the disease by inherent nature are less. \\
\hline Not much impact if any & $\begin{array}{l}\text { I feel less fearful. Although I understand my risk is not zero, is in fact two to three } \\
\text { times greater than the risk of the average person, I have more confidence. Every } \\
\text { time I say, forget my keys, I don't think, "Ah, this is how Alzheimer begins." }\end{array}$ \\
\hline & Was good to know I did not have $A P O E$ gene \\
\hline
\end{tabular}


eral women in the Family History Group commented that risk information had little impact or that the information learned was what they expected. On the other hand, the Genotype Group reported optimism and relief after learning that they did not carry an $\epsilon 4$ allele.

There are several reasons as to why the Genotype Group may have reported a more beneficial impact than the Family History Group despite the fact that both groups received a $29 \%$ percent lifetime risk of developing AD. Individuals in the study may have been more interested in the genetic tests results than a numeric risk estimate from the outset and thus focused more intently on the $A P O E$ genotype. Several studies have suggested public interest in predictive testing for $\mathrm{AD}$, and in susceptibility testing in general. For example, three recent studies surveyed interest in $\mathrm{AD}$ predictive testing, both in the general public and among at-risk individuals, and all found that a majority of respondents expressed interest in pursuing predictive testing. ${ }^{20-22}$ Another study showed that the lay public was generally optimistic about the potential benefits of genetic susceptibility testing. ${ }^{23}$ It is important to note, however, that interest in predictive testing often does not translate into actual test uptake, as was seen in the case of Huntington disease. ${ }^{24}$

The nature of the information presented as part of the risk assessment, as well as how the information was communicated by the genetic counselors, may have also contributed to participants' favorable perceptions of genetic information. The genetic counselors informed all individuals during the disclosure session that the numeric risk estimate was derived from population studies and also stressed that it was an approximation and not an exact number; therefore, some participants in both subgroups may have discounted the risk estimate. The risk estimate itself is a middle range number and was presented as a probability. It has been shown that individuals may not be comfortable with mathematics, statistics, and probabilities in genetic counseling sessions. ${ }^{25}$ Participants may have found it easier to process $A P O E$ genotype results as opposed to the probabilistic information because of the dichotomous nature of the genetic test results. Even though the results were presented as one of six possible genotypes, the information may have been interpreted as binary: either I have the risk gene and will develop the disease or I do not have the gene and will not develop the disease. The tendency for individuals undergoing genetic counseling to process risk information in a binary manner has been noted in prior genetic counseling research in both adult-onset and prenatal settings. ${ }^{26}$ Because the Genotype Group received genetic test results, they may have been able to process the information easier than the Family History Group who only received a numeric risk estimate of $29 \%$. This notion is supported by preliminary analyses of information recall in the REVEAL study, which indicated that participants were more likely to recall their genotype than their numeric risk estimate. $^{27}$

These findings may be consistent with concerns among the medical community that the public is influenced by popular media descriptions of genetics. In describing the term genetic exceptionalism, Thomas Murray states that genetic informa- tion is viewed as special by the public because it is treated as mysterious and powerful. ${ }^{11}$ The future and potential of genetic testing is often portrayed by the media in a sensational manner, which may lead to individuals placing more importance than appropriate on genetic information.

There also exists the concern that individuals who test negative for a susceptibility factor for a complex disorder such as $\mathrm{AD}$ may become complacent with respect to health behaviors despite the fact that they may still be at an increased risk for disease due to their family history. ${ }^{28}$ Studies on genetic testing and counseling for cancer that address this concern have reached contrasting conclusions, either showing that individuals that received a negative test result were less compliant to screening guidelines, ${ }^{29}$ or that receipt of a negative test result did not discourage engaging in recommended risk-reducing behaviors. ${ }^{30}$ In the current study, related but as yet unpublished analyses suggest (1) that $\epsilon 4$-negative participants and controls did not differ regarding the extent to which they engaged in health behaviors after risk disclosure, and (2) that the majority of $\epsilon 4$-negative participants correctly recognized that their risk of $\mathrm{AD}$ was still higher than people without family history of the disease.

There are some limitations to this study. Because the analysis called for the use of a subset of individuals from REVEAL study, our sample size was relatively small. Our participants are not representative of the general population at risk for $\mathrm{AD}$, given that they are predominantly White, all female, and with a high level of education and socioeconomic status. Also, because the majority of the participants entered the study with the hope of learning their APOE genotype, the women in the Family History Group may have reacted more negatively because they were disappointed and felt that useful information was being withheld. Comments from the Family History Group in Table 3 allude to disappointment in not receiving genetic test results. The genetic counselors did educate the participants that all would receive a numeric risk estimate incorporating gender and family history. However, because risk disclosure sessions were not recorded, we could not assess potential counselor and/or process variables that may have distinguished presentation of risk information between the two groups in the study. Another limitation that may have affected participants' interpretation of the risk assessment information, specifically those in the Genotype Group, is the lack of knowledge of the affected parent's genotype. Although participants were aware that parental genotype was not used in generating a numerical risk estimate, some women in the Genotype Group may have been concerned that their affected parent developed $\mathrm{AD}$ due to genetic factors other that APOE $\epsilon 4$ and were thus less confident in the risk estimate. During the risk disclosure setting, the genetic counselors discussed what information was used to generate a risk estimate while also discussing the limitations of providing a risk assessment for a disease in which additional susceptibility genes remain to be identified.

This study is unique because we were able to explore the impact of incorporating genetic susceptibility information into a risk assessment for Alzheimer disease and focus specifi- 
cally on how these test results affected AD risk perception compared to a risk estimate based on generalized epidemiologic considerations. Not only are the findings significant for $\mathrm{AD}$, they are also relevant for other complex disorders as more susceptibility genes are discovered. Further studies on determinants of risk perception in common, complex disease are clearly necessary. It will also be worthwhile to examine how inclusion of genetic susceptibility results may influence motivation to adopt health behaviors that may reduce disease risk.

\section{ACKNOWLEDGMENTS}

This study was supported by National Institute of Health grants RO1 HG/AG 02213 (REVEAL study), P30 AG13846 (Boston University Alzheimer Disease Center), and M01 RR00533 (Boston University General Clinical Research Center).

\section{References}

1. Lendon CL, Ashall F, Goate AM. Exploring the etiology of Alzheimer disease using molecular genetics. JAMA 1997;227:825-831.

2. Strittmatter WJ, Saunders AM, Schmechel D, Pericak-Vance M, Enghild J, Salveen GS et al. Apolipoprotein E: High-avidity binding to beta-amyloid and increased frequency of type 4 allele in late-onset familial Alzheimer disease. Proc Natl Acad Sci US A 1993;90:1977-1981.

3. Brodaty H, Conneally M, Gauthier S, Jennings C, Lennox A, Lovestone S. Consensus statement on predictive testing for Alzheimer disease. Alzheimer Dis Ass Disord 1995;9:182-187.

4. Farrer LA, Brin MF, Elsas L et al. Statement on use of Apolipoprotein E testing for Alzheimer disease. JAMA 1995;274:1627-1629.

5. Relkin NR, Tanzi R, Breitner J et al. Apolipoprotein E genotyping in Alzheimer's disease. Lancet 1996;347:1091-1095.

6. Burke W, Pinsky LE, Press NA. Categorizing genetic tests to identify their ethical, legal, and social implications. Am J Med Genet 2001;106:233-240.

7. Green RC. Genetic testing for Alzheimer's disease: has the moment arrived? Alz Care Quarterly 2002;208-214.

8. Khoury MJ, Thrasher JF, Burke W, Getting EA, Fridringer F, Jackson R. Challenges in communicating genetics: A public health approach. Genet Med 2000;2:198-202.

9. Slovic P, Fishchoff B, Lichtenstein S. Factors and fears: Understanding perceived risk. In: Schwing RC, Albers WA, eds. Societal risk assessment: How safe is safe enough? New York: Plenum Press, 1980:181-216.

10. Senior V, Marteau T, Weinman J. Impact of genetic testing on causal models of heart disease and arthritis: an analogue study. Psychol Health 2000;14:1077-1088.

11. Murray TH. Genetic exceptionalism and 'future diaries': Is genetic information different from other medical information? In: Rothstein MA, ed. Genetic secrets: Protecting privacy and confidentiality in the genetic era, vol 1. New Haven: Yale University Press, 1997:60-72
12. Hicken B, Tucker D. Impact of genetic risk feedback: perceived risk and motivation for health protective behaviours. Psychol Health Med 2002;7:25-36.

13. Genetic Risk Assessment for Familial hypercholesterolaemia Trial (GRAFT) Study Group. Psychological impact of genetic testing for familial hypercholesterolaemia in a previously aware population: a randomized controlled trial. Am J Med Genet 2004; 128A:285-293.

14. Lerman C, Gold K, Audrain J, Lin TH, Boyd NR, Orleans CT et al. Incorporating biomarkers of exposure and genetic susceptibility into smoking cessation treatment: effects on smoking-related cognitions, emotions, and behavior change. Health Psychology 1997;16:87-99.

15. Roberts JS, LaRusse SA, Katzen H, Whitehouse PJ, Barber M, Post SG et al. Reasons for seeking genetic susceptibility testing among first-degree relatives of people with Alzheimer disease. Alzheimer Dis Assoc Disord 2003;17:86-93.

16. Cupples LA, Farrer LA, Sadovnick AD et al. Estimating risk curves for first-degree relatives of patients with Alzheimer's disease: The REVEAL Study. Genet Med 2004; 6:192-196.

17. Lautenschlager NT, Cupples LA, Rao VS, Auerbach SA, Becker R, Burke J, Chui H et al. Risk of dementia among relatives of Alzheimer's disease patients in the MIRAGE study: What is in store for the oldest old? Neurology 1996;46:641-650.

18. Green RC, Cupples LA, Go R, Benke KS, Edeki T, Griffith PA et al, MIRAGE Study Group. Risk of dementia among white and African American relatives of Alzheimer's disease patients. JAMA 2002;287:329-336.

19. Farrer LA, Cupples LA, Haines JL, Hyman B, Kukull WA, Mayeux R et al. Effects of age, sex and ethnicity on the association between apolipoprotein E genotype and Alzheimer's disease: A meta-analysis. JAMA 1997;278:1349-1356.

20. Neumann PJ, Hammitt JK, Mueller C, Fillit HM, Hill J, Tetteh NA et al. Public attitudes about genetic testing for Alzheimer's disease. Health Affairs 2001;20:252264.

21. Roberts JS. Anticipating response to predictive genetic testing for Alzheimer's Disease: A survey of first-degree relatives. The Gerontologist 2000;40:43-52.

22. Green RC, Clark VC, Thompson NJ, Woodland JL, Letz R. Early detection of Alzheimer disease: methods, markers, and misgivings. Alz Dis Assoc Disorders 1997; 11(suppl 5):S1-S5.

23. Shaw JS III, Bassi KL. Lay attitudes toward genetic testing for susceptibility to inherited disease. J Health Psych 2001;6:405-423.

24. Quaid KA, Morris M. Reluctance to undergo predictive testing: The case of Huntington's disease. Am J Med Genet 1993;45:41-45.

25. Chase GA, Faden RR, Holtzman NA, Chwalow AJ, Leonard CO, Lopes C et al. Assessment of risk by pregnant women: implications for genetic counseling and education. Soc Biol 1986;33:57-64.

26. Lippman-Hand A, Fraser FC. Genetic counseling: provision and reception of information. Am J Med Genet 1979;3:113-127.

27. LaRusse S, Katzen H, Brown T, Barber M, Whitehouse P, Green RC et al. Participant recall of their own apolipoprotein $\mathrm{E}(A P O E)$ genotype and risk estimate after six weeks: results from the REVEAL Study. Neurobiol Aging 2002;23:S324.

28. Haga SB, Khoury MJ, Burke W. Genomic profiling to promote a healthy lifestyle: not ready for primetime. Nat Genet 2003;34:347-350.

29. Johnson KA, Trimbath JD, Petersen GM, Griffin CA, Giardiello FM. Impact of genetic counseling and testing on colorectal cancer screening behavior. Genet Med 2002;6:271-272.

30. Plon SE, Peterson LE, Friedman LC, Richards CS. Mammography behavior after receiving a negative BRCA1 mutation test result in the Ashkenazim: a communitybased study. Genet Med 2000;2:307-311. 